\title{
SIMULATION MODEL FOR IMPROVED PRODUCTION PLANNING AND CONTROL THROUGH QUALITY, CYCLE TIME AND BATCH SIZE MANAGEMENT
}

\author{
UDC: $\quad 658.5: 519.876 .5$ \\ Original Scientific Paper \\ Živko KOTEVSKI, Bojan JOVANOSKI, Robert MINOVSKI \\ Ss. Cyril and Methodius University in Skopje, Faculty of Mechanical Engineering, Department of Industrial \\ Engineering and Management, 1000 Skopje, Karpos II bb, Republic of Macedonia. \\ E-mail: bojan.jovanoski@mf.edu.mk
}

Paper received: 25.04.2015.; Paper accepted: 20.05.2015.

\begin{abstract}
Production planning and control (PPC) systems are the base of all production facilities. In today's surroundings, having a good PPC system generates lots of benefits for the companies. But, having an excellent PPC system provides great competitive advantage and serious reduction of cost in many fields. In order to get to a point of having excellent PPC, the companies turn more and more to the newest software tools, for simulations as an example. Considering today's advanced computer technology, by using the simulations in this area, companies will have strong asset when dealing with different kinds of wastes, delays, overstock, bottlenecks and generally loss of time. This model is applicable in almost all production facilities. Taking into account the different scrap percentages for the pieces that form the end product, a detailed model and analysis were made in order to determine the optimal starting parameters. At first all the conditions of the company were determined, conceptual model was created along with all assumptions. Then the model was verified and validated and at the end a cost benefit analysis was conducted in order to have clear results.
\end{abstract}

Key words: PPC, simulation, production, benefit, improvement.

\section{INTRODUCTION}

In today's business environment, technology development and speed of global industrial change, every minute counts. Any lost time means lost money, increased costs and ultimately leads to loss of customers, eventually loss of the entire business. This is why enterprises require dynamics and flexibility out of the systems for production planning and control, which would respond to these rapid changes and would keep losses to a minimum, allowing better management of company resources, (Jovanoski, 2010).

Production Planning and Control systems (PPC) represent the heart of the production and are subject of numerous studies by world experts like Zäpfel (1996), Harrison and Petty (2002), Zijm (2000) and many others. But as a threat everywhere linger the fact that simulations may be useful in solving the problems in the planning of production, and therefore are often encountered in research papers, (Minovski and Jovanoski, 2009).

Simulations represent imitation of some process in the real world. Process simulation often requires generating of a model that will represent the key characteristics of the selected system or process and will present its behavior. Based on this information, the model is actually a system / process over time. The key in simulations is collecting reliable and valid information for the system / process, its characteristics and behaviors, the ability to simplify them and to calculate assumptions and assertions in the model so that it can be validated on the basis of the results of the simulation and, if possible, the real system.

Persistent global changes require constant changes and revisions of production systems, and inevitably lead to permanent changes to the system for production planning and control, (Jovanoski, 2009). However, sticking to the basic tenets in PPC 
and sticking to the mission and vision, the highest tenets in the enterprise, the organization sets an excellent foundation for movement in the right direction and reduces losses in the production process.

\section{RESEARCH METHODOLOGY}

The basic methodology for this research is the following: determination of the problem, implementation of the modeling and simulation for solution of the problem and evaluation of the solution. It has to be emphasized that this research is a part of higher, more comprehensive research on Production Planning and Control. So the methods and tools for carrying out the first step are not enclosed in this paper. For the second step the methodology of Discrete Event Simulations (DES) is used, according Banks (1998). Additionally, software packages for simulation are being used as a tool for visual display of the simulation, (Jovanoski et al., 2012). The third step is undertaken with simple cost-benefit analysis.

The key researches and information are collected in a production facility, where this research and validation of the simulation were made.

\section{SIMULATION MODEL}

In order to introduce the simulation, the methodology of Banks for DES simulation is used. It has several steps that are followed in this research.

\section{Defining the problem}

In order to minimize the wastes, delays, loss of time, bottlenecks and overstocks, one of the most important factors is the correct launching of the working orders and a proper set of the batch size in production. In today's competitive surroundings, this problem pops up as one of the main issues of the companies.

\section{Defining the target and creating project plan}

Taking into account the new directions of thinking (lean manufacturing, JIT), it is particularly important to keep minimum amounts of stock. The purpose of this simulation is to obtain accurate amounts of quantity that needs to be launched in production and thereby solve a big everyday problem.
The main objective of the project is to deliver 50 isolating cocks G1/2 to the end customer, and thereby not to have unnecessary number of parts in stock. Therefore the result of the simulation is very useful and can be applied for almost all products in this facility and in any other production facility, adjusted to its parameters and quantities.

\section{Creating conceptual model}

At the stage of creating conceptual model,the first thing is introduction of inputs, material flow of movement and some additional information that are important for simulation.

As an object of interest, the isolating cock will be reviewed with all of its basic elements. The cock is consisted of 7 different parts and certain amount of purchasing items, which are not relevant to the research because they are always on stock and with a certified quality level.

In order to make the model, it is necessary that everybody knows and understands the flow of the material in the facility, shown in Figure 1. The processes in dashed border line are areas that need special attention and will be the subject of the research. The solid lined white arrows show the proper way of material movement, and the grey arrows show worst case scenario where material goes if there are problems in the process (scrap, rework etc.). Regular arrows show possible movements if there are smaller issues.

\section{Collecting information}

For this simulation, information from the information system of the current production facility will be used. As shown in the creation of the concept model, the subject of analysis will be isolated cock with catalog number 391580U. It consists of seven different positions. The production times are shown in the following Table 1 and they show the time required for production of the complete batch.

\section{Formulating the model}

The model was created using the Siemens Plant Simulation software. After the complete data have been entered (from all the information gathered during the research) into the software, the simulation model is shown in Figure 2. 


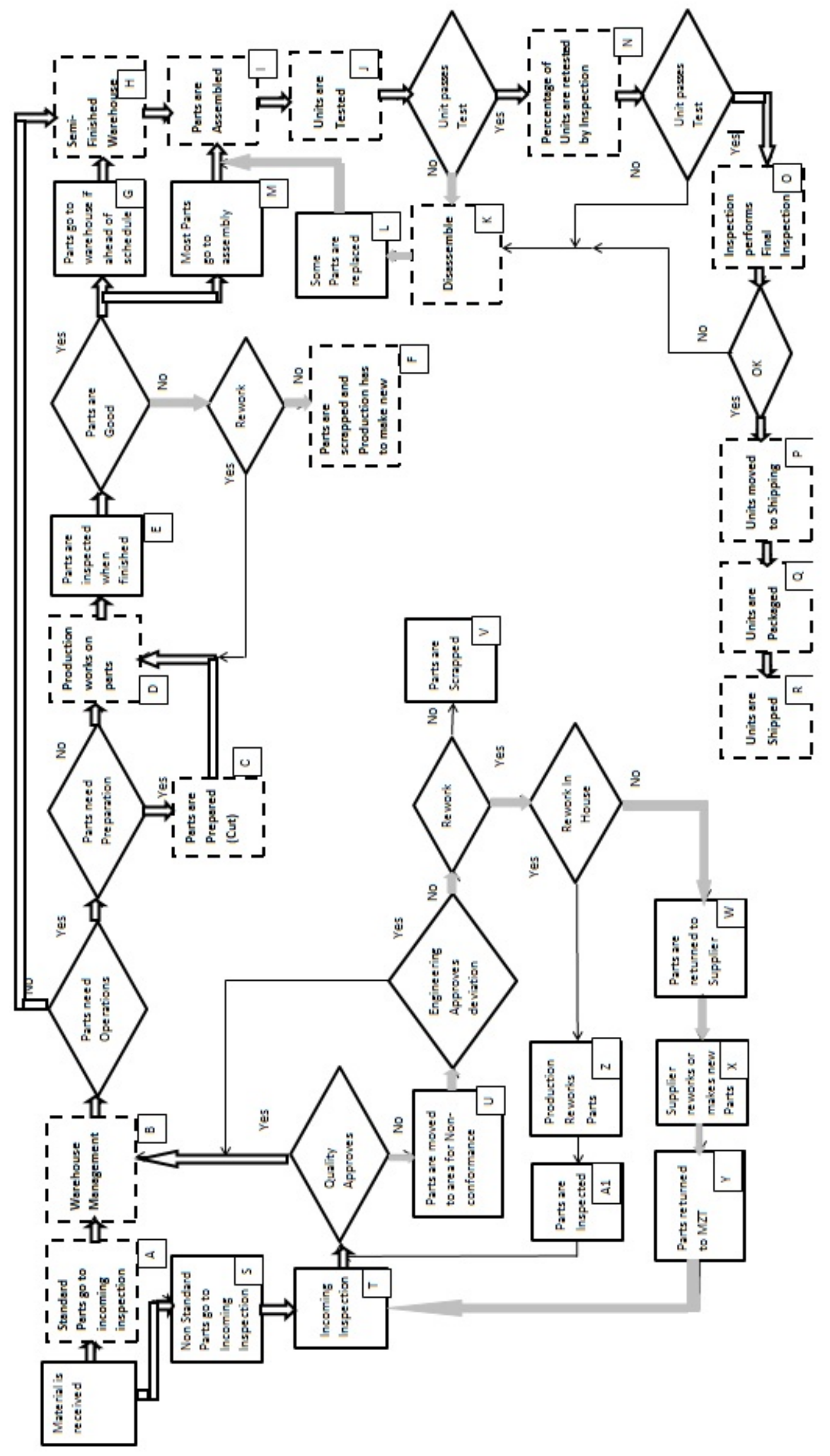

Figure 1: Material flow 
Table 1: Production times (in minutes)

\begin{tabular}{|c|l|c|c|c|c|}
\cline { 2 - 6 } \multicolumn{1}{c|}{} & Process & A & B & C & D \\
\hline $\begin{array}{c}\text { Part } \\
\text { number }\end{array}$ & Part name & $\begin{array}{c}\text { Incoming } \\
\text { control }\end{array}$ & Transport & $\begin{array}{c}\text { Preparation } \\
\text { of material }\end{array}$ & Machining time \\
\hline 391581 & Housing & 15 & 25 & 200 & 13,985 \\
\hline 391506 & Handle & 15 & 25 & 150 & 2,450 \\
\hline 391582 & Slider & 15 & 25 & 150 & 4,528 \\
\hline 391504 & Cap & 15 & 25 & 60 & 982 \\
\hline 391503 & Spindle & 15 & 25 & 0 & 2,450 \\
\hline 391507 & Outside slider & 15 & 25 & 90 & 8,624 \\
\hline 391505 & Cover & 15 & 25 & 90 & 7,238 \\
\hline
\end{tabular}

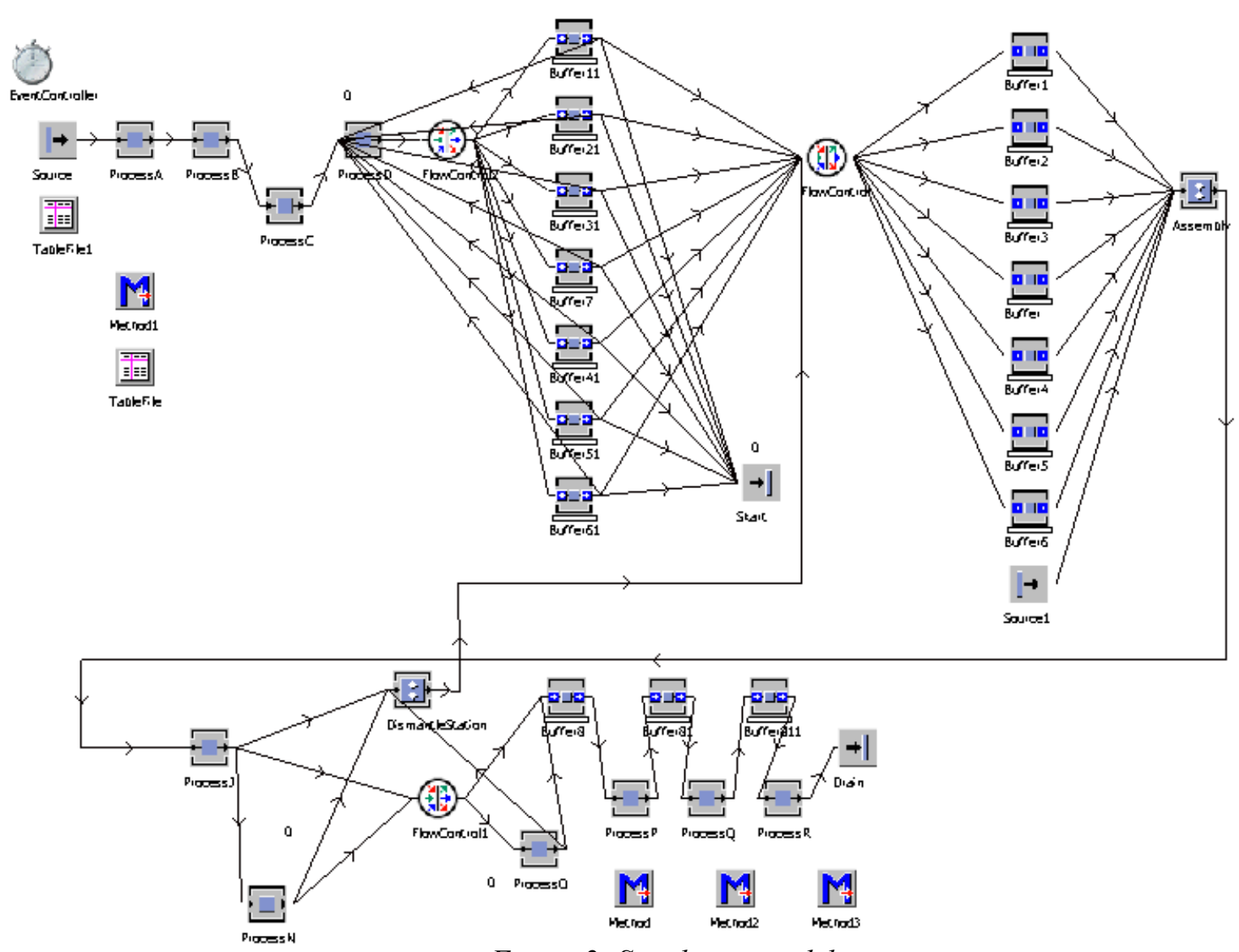

Figure 2: Simulation model

\section{Verification}

The ultimate target of the model is to receive the proper quantity for production in order to have minimal (or zero) stock. So at this stage it is crucial to have all the conditions and parameters entered, to finally get the finished product.

At the first test, the processes start with 50 pieces for all parts and at the end, 50 end products are delivered. This means that the model is well coded and can be said to be verified.

After that, the information about the different scrap rate for every part has been entered. As an input, knowing that the target is to have 50 end products delivered, the process will start with launching of 60 pieces for all items. As a result of the simulation, an information from the software states that 55 final products have been assembled and tested, and they are ready to be delivered.

\section{Validation}

In this case, the target is to deliver 50 end products to the customer. In the previous text it was said that there are 60 pieces of each item in production. As a result, there are 55 isolating cocks assembled and 5 isolating cocks on stock. Apart from that, the 
inventory of several items that were not assembled is increased. This is shown in Table 2.

This simulation shows that not only did production produced 5 end products more, but they produced 5 Housings extra, 4 Handles, 4 sliders etc. This is in line with the actual state of the production process and can be confirmed that the model is validated.

With a simple math, the calculation states the exact quantity (last column - Result) that should be launched in production. By putting this information again in the model, the result is shown in Table 3.

Table 2: Analysis of the model

\begin{tabular}{|c|l|c|c|c|c|c|c|}
\hline $\begin{array}{c}\text { Part } \\
\text { number }\end{array}$ & Part name & $\begin{array}{c}\text { Launched } \\
\text { quantity }\end{array}$ & Assembled & $\begin{array}{c}\text { Remaining } \\
\text { stock }\end{array}$ & Difference & Target & Result \\
\hline 391581 & Housing & 60 & 55 & 5 & 0 & 50 & 50 \\
\hline 391506 & Handle & 60 & 55 & 4 & +1 & 50 & 51 \\
\hline 391582 & Slider & 60 & 55 & 4 & +1 & 50 & 51 \\
\hline 391504 & Cap & 60 & 55 & 0 & +5 & 50 & 55 \\
\hline 391503 & Spindle & 60 & 55 & 3 & +2 & 50 & 52 \\
\hline 391507 & Outside slider & 60 & 55 & 2 & +3 & 50 & 53 \\
\hline 391505 & Cover & 60 & 55 & 3 & +2 & 50 & 52 \\
\hline
\end{tabular}

Table 3: Final results

\begin{tabular}{|c|l|c|c|c|c|c|}
\hline $\begin{array}{c}\text { Part } \\
\text { number }\end{array}$ & Part name & $\begin{array}{c}\text { Launched in } \\
\text { production }\end{array}$ & Assembled & $\begin{array}{c}\text { Remaining } \\
\text { stock }\end{array}$ & Difference & $\begin{array}{c}\text { Ready to } \\
\text { deliver }\end{array}$ \\
\hline 391581 & Housing & 50 & 50 & $\mathbf{0}$ & 0 & 50 \\
\hline 391506 & Handle & 51 & 50 & $\mathbf{0}$ & 1 & 50 \\
\hline 391582 & Slider & 51 & 50 & $\mathbf{0}$ & 1 & 50 \\
\hline 391504 & Cap & 55 & 50 & $\mathbf{0}$ & 5 & 50 \\
\hline 391503 & Spindle & 52 & 50 & $\mathbf{0}$ & 2 & 50 \\
\hline 391507 & Outside slider & 53 & 50 & $\mathbf{0}$ & 3 & 50 \\
\hline 391505 & Cover & 52 & 50 & $\mathbf{0}$ & 2 & 50 \\
\hline
\end{tabular}

Table 4: Cost-Benefit analysis

\begin{tabular}{|c|l|c|c|c|c|c|r|}
\hline $\begin{array}{c}\text { Part } \\
\text { number }\end{array}$ & Part name & $\begin{array}{c}\text { Total } \\
\text { minutes } \\
\text { spent }\end{array}$ & $\begin{array}{c}\text { Total } \\
\text { hours } \\
\text { spent }\end{array}$ & $\begin{array}{c}\text { Stock } \\
\text { remaining }\end{array}$ & $\begin{array}{c}\text { Hours spent } \\
\text { for production } \\
\text { of the stock }\end{array}$ & $\begin{array}{c}\text { Hourly } \\
\text { profit from } \\
\text { machine }\end{array}$ & $\begin{array}{c}\text { Total } \\
\text { profit }\end{array}$ \\
\hline 391581 & Housing & 14225.00 & 237.08 & 5 & 21.55 & 4.13 & $89.06 €$ \\
\hline 391506 & Handle & 2640.00 & 44.00 & 4 & 3.20 & 4.13 & $13.22 €$ \\
\hline 391582 & Slider & 4716.00 & 78.60 & 4 & 5.72 & 4.13 & $23.62 €$ \\
\hline 391504 & Cap & 1082.00 & 18.03 & 0 & 0.00 & 4.13 & $-€$ \\
\hline 391503 & Spindle & 2490.00 & 41.50 & 3 & 2.26 & 4.13 & $9.35 €$ \\
\hline 391507 & Outside slider & 8754.00 & 145.90 & 2 & 5.31 & 4.13 & $21.92 €$ \\
\hline 391505 & Cover & 7368.00 & 122.80 & 3 & 6.70 & 4.13 & $27.68 €$ \\
\hline
\end{tabular}

\section{RESULTS}

Looking at the last step of the simulation model, the results are getting clear. This shows that if there are 50 housings, 51 handles, 51 sliders, 55 caps, 52 spindles, 53 outside sliders and 52 covers launched in production, the result would be 50 isolating cocks and no single parts on stock. This was the starting point and the goal of the research.
In order to confirm the importance of this activity, a short cost benefit study was made. With this activity, in the worst case scenario, there will be a production time saving for 5 housings, 4 handles, 4 sliders, 3 spindles, 2 outside slider and 3 cover.

In order to make a calculation for another product, with already set base as shown, for one man to do the analysis, it would take him up to 5 days. Average wage in Macedonia is $488 €$ for 20 
working days per month, which means that this analysis would cost $122 €$.

On the other hand, in the production facility where the research has been made, there are 90 machines. Last year the total income was about 18 million and the profit is around $8 \%$, or 1.44 million. This means that there is a profit of $4.13 €$ per machine per hour. Total available hours per year are $348,480.00 \mathrm{~h}$. The analysis is more clearly shown in Table 4.

So the result is: $122 €$ spent and $184.86 €$ saved. In this calculation are not calculated the money that are saved with the decrease in the stock level, like better cash flow, less storage space, less storage movement etc. Plus, this calculation is based on a single product, and in the analyzed production facility, there are more than 100 different products that are being sold monthly.

\section{CONCLUSION}

This paper reveals one of many ways where simulations can be very helpful in production oriented facilities. This particular model shows that we can lower the wastes by lowering the stock level and shorten the machining time for the parts that would be left on stock. Considering today's highly competitive market and relatively well known technologies, minimizing the wastes might be the biggest competitive advantage and every tool that might have an influence in that field should be studied and is possibly worth invested. The benefit will be felt by the company on more than one level.

\section{REFERENCES}

Banks, J. (Ed.). (1998). Handbook of simulation. New York: Wiley.

Harrison, D. K., \& Petty, D. J. (2002). Systems for Planning and Control in Manufacturing: Butterworth-Heinemann.

Jovanoski, B. (2009). Optimizing the process of enterprise restructuring using the simulation [in Macedonian]. Master thesis.

Jovanoski, D. (2010). Production Systems [in Macedonian]. Skopje, Macedonia: Ss. Cyril and Methodius University in Skopje, Faculty of Mechanical Engineering.

Jovanoski, D., Minovski, R., Kostovska, G., \& Jovanovski, B. (2012). Modeling \& simulation as tools for optimisation of material flow in production systems. Journal for Technology of Plasticity, 37(1), 22-34.

Minovski, R., \& Jovanoski, B. (2008). Methodology for overall company restructuring and the simulation as added value. WINGBusiness, TU Graz, October 2008, Austria.

Zäpfel, G. (1996). Grundzüge des Produktions- und Logistikmanagement. Berlin-New York: de Gruyter Verlag.

Zijm, W. H. M. (2000). Towards Intelligent manufacturing planning and control systems. $O R$ Spectrum, 22(3), 313-345. 